\begin{tabular}{lcl}
\hline \multicolumn{1}{c}{ PKS } & REVISTA DE GEOGRAFIA & \multicolumn{1}{c}{ OJS } \\
$\begin{array}{lcc}\text { PUBLIC } \\
\text { KNOWLEDGE } \\
\text { PROJECT }\end{array}$ & $\begin{array}{c}\text { DECIFE) } \\
\text { OPEN } \\
\text { RROL }\end{array}$ & $\begin{array}{l}\text { JOURNAL } \\
\text { SYSTEMS }\end{array}$ \\
\hline
\end{tabular}

\title{
R-EXISTÊNCIAS SOCIAIS PELA VIDA: CAMPONESAS E CAMPONESES DO QUE HOJE É SUAPE (BRASIL) E DAS ZONAS DE RESERVA CAMPONESAS (COLÔMBIA)
}

\author{
Beatriz Barbosa da Silva ${ }^{1}$ \\ ${ }^{1}$ Universidade Federal de Pernambuco. E-mail: biabarbosa42@gmail.com
}

Artigo recebido em 31/05/2018 e aceito em 15/06/2018

\begin{abstract}
RESUMO
O livro R-existências sociais pela vida: camponesas e camponeses do que hoje é Suape (Brasil) e das Zonas de Reserva Camponesas (Colômbia), traz para a análise os conflitos instaurados nos territórios de Suape, em Pernambuco, e nas Zonas de Reserva Camponesas, localizadas na Colômbia. Por meio de uma proposta descolonial, são retratadas as r-existências dos povos agrários da América Latina, através de suas conquistas legais e de suas lutas por territórios de vida. Diante deste contexto, o presente trabalho, que tem como autora a geógrafa Mercedes Solá Pérez, ao apresentar a realidade dos camponeses/as do Brasil e da Colômbia, propõe a construção de novas epistemes que considerem a existência de outras formas de conhecimento.
\end{abstract}

Palavras-chave: R-existências; Descolonial; Territórios; América Latina.

\section{SOCIAL R-ESISTANCE FOR LIFE: PEASANTS OF WHAT IS NOW SUAPE (BRAZIL) AND THE RESERVE ZONES PEASANTS (COLOMBIA)}

\begin{abstract} in presenting the reality of peasants in Brazil and Colombia.

Key-words: Resistances; Decolonial; Territories; Latin America.
\end{abstract}

The book R-existências sociais pela vida: camponesas e camponeses do que hoje é Suape (Brasil) e das Zonas de Reserva Camponesas (Colômbia), brings to the analysis the conflicts established in the territories of Suape, in Pernambuco, and in the Zona de Reservas Camponesas, located in Colombia. By means of a decolonial proposal, the resistances of the agrarian peoples of Latin America are portrayed, through their legal achievements and their struggles over territories of life. In view of this context, the present work, authored by the geographer Mercedes Solá Pérez, proposes the construction of new epistemes that consider the existence of other forms of knowledge 


\section{RESENHA}

Outros mundos. Este é um dos temas abordados pela geógrafa Mercedes Solá Pérez em seu livro R-existências sociais pela vida: camponesas e camponeses do que hoje é Suape (Brasil) e das Zonas de Reserva Camponesas (Colômbia), a existência de outros mundos, outros modos de viver e de r-existir. Pérez analisa os conflitos e r-existências presentes nos territórios dos camponeses/as de Suape com a implantação do Complexo Industrial e Portuário de Suape (CIPS) em Pernambuco, e das Zonas de Reserva Camponesas (ZRC) localizadas na Colômbia, demonstrando as especificidades e elementos em comum na luta pelo território e pela vida destes camponeses/as.

O mundo moderno-colonial não tem a capacidade de comportar todos os mundos e modos de vida existentes na sociedade. De acordo com a autora, o sistema mundo modernocolonial nega a existência de outros mundos, por meio da repressão, da linearidade cega para outros caminhos e outras formas de ser. Entretanto, a diversidade, os saberes e as cosmovisões estão presentes, mesmo em uma sociedade que privilegia o des-envolvimento ${ }^{1}$. Assim, os povos lutam e resistem para se reafirmar e negar o modelo imposto por uma sociedade alienígena.

A vida se apresenta como o tema central do livro; a vida dos povos do mar, do campo, da floresta e da cidade, essa vida que surge na luta pelos seus territórios e por autonomia, nas resistências cotidianas. Em seu livro, Pérez demonstra como o resistir vira sinônimo de lutar, como esses povos marginalizados pela colonialidade, tratados como inferiores e atrasados, r-existem e afirmam suas identidades no cultivo realizado em seu território, nas danças, nas pluralidades dos modos de vida. Ao resgatar o histórico de conflitos presentes nos territórios de Suape e da Zonas de Reserva Camponesas (ZRC) demonstrando o braço violento do Estado, que aliado ao capital expropria, discrimina e nega a humanidade dos povos, representando-os como objetos que devem ser retirados para a continuidade da reprodução capitalista —, Pérez apresenta a outra face destes conflitos, o lado que o Estado e o capital buscam mascarar: os mundos de r-existências, os territórios de vida que existem e persistem em uma lógica que se propõe ir além da des-envolvimentista, além das barreiras impostas pela colonialidade do poder, do saber e do ser. Os conflitos têm que ser

\footnotetext{
${ }^{1} \mathrm{O}$ termo des-envolvimento é um conceito utilizado pela autora, referindo-se a Carlos Walter Porto-Gonçalves, que entende esta expressão como a retirada da autonomia e do envolvimento das populações com os seus territórios. O des-envolvimento individualiza e segrega os povos, separando-os entre si e em relação à natureza. Des-envolver é impor dinâmicas vindas de fora para as populações, desconsiderando seus saberes e culturas. (PORTO-GONÇALVES, 2006)
} 
evidenciados, a violência tem que ser denunciada, assim como a mercantilização da natureza e dos seres humanos. Contudo, mais importante que isso são as lutas, as reivindicações, a construção de redes de r-existência que consigam alcançar todos os povos e comunidades, formando um território de vida que considere todos os mundos.

O discurso reducionista moderno/colonial nos faz acreditar nesta fábula cruel, de que há um caminho de pedras a ser seguido e no seu fim estará o progresso, o primeiro mundo, homogeneizador e mercantilista, que afirma o econômico em detrimento do social. Neste primeiro mundo, não há espaço para diferenças, a não ser quando transformadas em desigualdades; a diversidade vira atraso, e os saberes não ocidentais, folclores. Em seu livro, Mercedes Solá Pérez não só critica este modelo engessado e monopolizante do sistema mundo moderno/colonial, mas apresenta diferentes formas de viver, agir e pensar. Desde a linguagem como ferramenta essencial na luta dos povos indígenas, que afirmam suas identidades e autonomias através de representações que contemplem suas cosmovisões, até o cultivo de árvores frutíferas de uma camponesa no "que hoje é Suape" (SOLÁ, 2017, p. 37), os povos constroem novas formas de r-existência e persistem na luta contra este caminho de pedras imposto por uma sociedade eurocentrada, que enxerga o des-envolvimento como única forma de adquirir qualidade de vida.

A colonialidade estruturou a relação entre os países, naturalizando decisões políticas, como as fronteiras que foram delineadas arbitrariamente, em grande parte por países europeus, fazendo com que relações que foram construídas no período da colonização continuassem vigentes. Esta herança colonial pode ser percebida no que Pérez chama de modelo exportador neocolonial. Na América Latina, países como o Brasil e a Colômbia mantêm relações privilegiando os de fora, a exportação torna-se palavra de ordem; para que isto ocorra, a natureza é posta a venda, e os povos e comunidades são assassinados ou 'realocados'. Os de fora, países estrangeiros, como os Estados Unidos, instalam empresas nestes territórios com o apoio do Estado brasileiro ou colombiano, e possuem carta branca para impor suas regras, mesmo que nelas a violência esteja inscrita. O mundo percebido por meio desta lente moderno-colonial retira a humanidade dos povos vistos como obstáculos para a reprodução do capital, transforma a natureza em recurso, o autoconsumo em subsistência. Por conta disso, a proposta é utilizar a lente das r-existências, que descolonize as relações, que considere outras formas de ser e pensar. 
A categoria 'camponês' é utilizada pela autora por conta de sua complexidade. As comunidades que residem nos territórios de Suape e da Zona Camponesa, estabelecem uma diversidade de relações com suas terras, a identidade é plural, com dezenas de mundos presentes em um só. Por conta disso, a identidade camponesa abrange esses mundos e representa esses dois povos e suas lutas. Uma luta que é por autonomia, a autonomia de ir além do modelo exportador neocolonial, ir além do des-envolvimento e de um capitalismo que busca se expandir e engolir outros mundos, outras formas de viver.

$\mathrm{O}$ discurso caracteriza-se como uma ferramenta fundamental utilizada pelos grupos hegemônicos, aliados ao Estado, para promover a expansão do capital. O discurso serve como uma máscara, que ao velar a estrutura violenta e opressora que carrega, legitima suas práticas e relações. Neste contexto, as questões sociais são esvaziadas, o Estado dá mais repercussão a problemáticas sociais menores como forma de invisibilizar a estrutura colonial que reproduz. No primeiro capítulo, intitulado Camponesas e camponeses: seus territórios e suas rexistências, Mercedes demonstra como o discurso ambiental distorcido, promovido pelas empresas do CIPS é utilizado para legitimar sua instalação e justificar a expropriação dos camponeses de seus territórios. A presença de mata atlântica na região é utilizada na propaganda das empresas do CIPS como forma de defender um falso ambientalismo, que apresenta como objetivo central a expansão do capital.

Um dos elementos estruturadores da sociedade moderno-colonial é o individualismo. As práticas coletivas são criminalizadas, e o homem, no singular, racional branco/europeu apresenta-se como o ideal; e é este individualismo que Mercedes Solá denuncia ao evidenciar como o Estado, e as empresas do CIPS no caso de Suape, constroem um campo de insegurança e proibições, no qual o camponês é expulso do seu território e realocado para áreas onde fica impossibilitado de exercer sua cultura, com o objetivo de individualizar, proletarizar e transformá-lo em força de trabalho para o capital. A chegada de grandes empresas nestes territórios também modifica a dinâmica interna destas comunidades. Pérez demonstra como após a instalação do CIPS houve um aumento da violência e de casos de gravidez. É imposta aos camponeses/as uma nova lógica, e é no cotidiano, na proibição, na vigilância, que essas comunidades mais sentem a violência do capital. No entanto, também é no dia a dia que estes povos se recriam, resistindo e buscando por uma autonomia libertadora. Ainda no primeiro capítulo, Mercedes, utilizando como referência os estudos do cientista 
político James Scott, apresenta três formas de r-existir: as r-existências cotidianas, públicas, e a última proposta pela autora, as de aliança.

A r-existência cotidiana manifesta-se na vida dos camponeses/as, nas práticas diárias que reafirmam suas identidades e seus modos de vida. Os trechos das entrevistas realizadas por Pérez durante suas idas a campo transmitem esta luta pela vida, tendo como elemento em comum a busca pela autonomia. A segunda forma de r-existência são as públicas. É neste modo de r-existir, que a importância da visibilidade das lutas é evidenciada. As resistências e persistências dos povos tradicionais, originários, camponeses/as, tecem redes de r-existências que serão disseminadas por outros mundos e territórios, fortalecendo a luta, construindo dinâmicas que comecem de dentro, criando um pensamento que seja contra-hegemônico, descolonial e plural. Os modos públicos de r-existências caracterizam-se pela luta coletiva, pelas ocupações e pela autonomia na rua, na visibilidade dos povos para outros povos.

Mercedes Solá ainda aponta para uma terceira forma de r-existência, a entre alianças. As ferramentas utilizadas pelo sistema mundo moderno/colonial para invisibilizar e criminalizar as comunidades tradicionais e originárias acarreta na necessidade das lutas e rexistências serem evidenciadas e estarem presentes em todos os meios, mesmo que os sujeitos que vivenciam essas lutas não estejam presentes fisicamente. As alianças caracterizam-se pela comunicação, pela visibilidade, pela desnaturalização da colonialidade, a partir de ONGs, instituições e pesquisadores que se identifiquem com as lutas e tragam para debate os conflitos, as resistências, que se aliem a estes povos com um objetivo em comum, o de construir uma sociedade onde caibam outros mundos.

Dando seguimento ao debate, no segundo capítulo do livro, Políticas de desenvolvimento do modelo primário exportador neocolonial - conflitos no que hoje é Suape, no Brasil e América Latina, a autora traz um histórico de conflitos e organizações, utilizando de diferentes escalas, desde Suape até a América Latina, para demonstrar as relações que se perpetuam ao longo da história e os processos que levaram à atual configuração do que hoje é Suape e da ZRC na Colômbia.

Ao resgatar os processos históricos de Pernambuco, um elemento em comum que surge em todos os períodos é o da concentração de terras. Desde as sesmarias, passando pela Lei de terras (1850), até a expansão do agronegócio, é possível perceber a hereditariedade do modelo colonial e exportador, que age por meio de ciclos de exploração, concentrando grandes parcelas de terras nas mãos de grupos da elite que, para se afirmarem, submetem a 
população a trabalhos precários, abrindo passagem para o progresso e deixando pelo caminho povos violentados, assassinados e expulsos de seus territórios. Contudo, Pérez também demonstra o outro lado, o da vida. Aprofundando-se na história dos povos que resistiram a este modelo exportador neocolonial, a autora, ao apresentar os conflitos e opressões sofridas por estas comunidades, traz para a sua análise o histórico de resistências, das fugas destas imposições feitas pelos senhores de terras, da constante busca por autonomia e de reprodução material e imaterial.

As políticas promovidas pelo Estado, que buscam des-envolver o país, ou seja, se inserir no modelo neocolonial, são viabilizadas por meio da instalação de megaprojetos, que apresentam em suas propagandas um cunho social. Nos panfletos e no discurso, os projetos possuem benefícios sociais e ambientais. Entretanto, na práxis estes mesmos projetos são os que expulsam as comunidades, mercantilizam a natureza e submetem a população a empregos temporários e subalternizados, obrigando o trabalhador a oferecer sua força de trabalho a condições sub-humanas de exploração e extração, criminalizando as reivindicações e impondo sua lógica a partir da negação das outras formas de vida. Levando em conta este cenário de violência, o Estado fornece programas sociais com o objetivo de amenizar e silenciar as populações que ficam vulneráveis às decisões tomadas pelas empresas instaladas em seus territórios. Segundo Pérez, por mais que estes programas forneçam mudanças na qualidade de vida destas pessoas, as transformações não são estruturais; o interesse do Estado e dos grupos hegemônicos é a de uma mudança superficial como forma de apaziguar a destruição causada pela necessidade do capital de se expandir, mas a estrutura moderno/colonial continua inabalável.

De acordo com a autora, o público-alvo destes projetos são os empresários e os grupos que possibilitam a reprodução do capital. Assim, são diversos os impactos ambientais causados pelas empresas nos territórios, tais como: a poluição dos rios, impossibilitando a pesca, a contaminação das águas, fazendo com que a água potável seja escassa para as comunidades, o desmatamento, destruindo a biodiversidade da região e consequentemente impactando no cultivo dos camponeses/as. Estas problemáticas não afetam as indústrias localizadas ao redor. Isto porque a água potável, escassa nas comunidades camponesas, encontra-se em abundância dentro dos complexos industriais. As empresas construídas no território detêm todos os meios naturais da região, obrigando os camponeses/as a migrar de suas terras em busca de qualidade de vida. No entanto, Pérez, ao apresentar a realidade dos 
camponeses/as de Suape e das ZRC, demonstra que apesar de sofrerem e estarem vulneráveis a estas violências impostas pelas empresas ou pelo próprio Estado, estas comunidades se impõem e reivindicam sua autonomia, negando o lugar de passivos e tornando-se protagonistas de suas lutas.

De acordo com a autora, este desejo de modernização, marginalizando a questão agrária, tem como objetivo central construir um cenário favorável à circulação do capital, potencializando o modelo neocolonial e beneficiando uma parcela mínima da população. Pérez utiliza como exemplo a atuação da Superintendência de Desenvolvimento do Nordeste - SUDENE (criada em 1959), e em Pernambuco, a Companhia de Revenda e Colonização CRC, instituições do Estado que tinham como intuito atuar na realização da reforma agrária, mas que possuem como finalidade a reprodução do capital. Estes órgãos acabam por auxiliar uma parcela limitada de camponeses/as, estabelecendo normas de produção de alimentos, demonstrando que apesar de surgirem como meios de auxílio na luta destas comunidades, a balança pende para o lado da reprodução capitalista e do modelo exportador colonial.

Baseando-se nos processos históricos de ocupação e na atual configuração de conflitos presentes nos territórios de Suape e das ZRC, Pérez propõe novas relações entre as comunidades camponesas e o Estado ou as empresas privadas, uma comunicação que considere a autonomia e os direitos de escolha destes sujeitos, relações que os percebam enquanto um povo que tem seus modos de vida e suas dinâmicas internas, e que não deve ser obrigado a se adaptar a imposições vindas de fora.

Em seu terceiro capítulo, chamado As r-existências que disseminam-se - Brasil. Colômbia, Pérez aponta os marcos legais dos povos agrários do Brasil e da Colômbia, demonstrando a partir deles as r-existências construídas em seus territórios. Mas, como ela evidencia, "apesar desses marcos legais existirem, os pesos e as medidas que são aplicadas para essas leis não são iguais a respeito daqueles marcos legais que beneficiam os latifundiários" (PÉREZ, 2017, p. 160). Mesmo com o Estado preterindo estes marcos legais e burocratizando a efetivação dessas leis, o valor simbólico que eles carregam para os povos e comunidades agrárias é imenso. Eles representam a afirmação de suas identidades, a possibilidade de se reconhecerem enquanto camponeses/as, indígenas, quilombolas. Com isso, neste capítulo, Pérez constrói uma síntese destes marcos legais, buscando elementos em comum entre as lutas dos povos agrários, tanto da Colômbia quanto do Brasil. 
Ao retomar o debate sobre a autonomia dos povos tradicionais e originários, a autora identifica que autonomia não se limita a negação ao Estado e ao sistema moderno/colonial; existem diversas formas de autonomia, e muitas comunidades ainda necessitam do auxílio do Estado para adquirirem seus territórios e se reproduzirem. Assim, a atuação do Estado, de acordo com o concedimento e determinações estabelecidas pela comunidade, podem auxiliar nas suas autonomias e nos seus modos de vida.

No entanto, ao mesmo tempo que o Estado surge como um elemento contributivo para as lutas e r-existências dos povos, reconhecendo suas identidades e estabelecendo os marcos legais, ele pode intensificar as políticas neoliberais que expropriam estas comunidades de seus territórios. Esta relação de veneno e antídoto, mostra a importância das três formas de r-existir apresentadas no primeiro capítulo deste livro. Pérez identifica que as r-existências não terminam na conquista dos territórios, mas continuam nos debates, na construção de uma educação específica e diferenciada, no cultivo agroecológico, na organização de assembleias, construindo redes coletivas de lutas e r-existências. Com base nisso, "podemos inferir que, o que se apresenta como essencial é a vida em si, pois é ela, em todas as esferas, a que se coloca em questão diante da continuação da reprodução do capital.” (PÉREZ, 2017, p. 195)

No quarto e último capítulo, Justiça territorial, pós-desenvolvimento $e$ descolonialidade como lutas pela vida, Mercedes Solá Pérez, a partir de suas vivências junto às comunidades, busca compreender a atualidade da questão agrária e das r-existências a partir de três conceitos: o de justiça territorial, pós-desenvolvimento e descolonialidade.

A justiça territorial, segundo a autora, apresenta um caráter urgente. Tendo como base as definições de justiça ambiental, espacial e social, o conceito proposto por Pérez é construído a partir da percepção do território como um elemento central na luta dos povos agrários. O território apresenta-se como o meio dos povos reproduzirem e darem continuidade a suas culturas, aos seus saberes e cosmovisões, no qual as pessoas estabelecem relações identitárias e ancentrais, ultrapassando o viés econômico e inserindo-se em todos os aspectos da vida dessas comunidades. É ao levar em conta estas relações que Pérez apresenta o conceito de justiça territorial como o fio condutor, a forma de reconhecer a importância do território na vida dos povos tradicionais e originários.

Em seguida, a autora aborda o conceito de pós-desenvolvimento. Para isso é feita uma breve análise sobre a ideia de desenvolvimento e os processos nos quais está inserido. $\mathrm{O}$ desenvolvimento, como um ideal homogenizador, surge aliado à modernização, como forma 
de dividir e individualizar as relações, estabelecendo uma linearidade que vai desde os povos primitivos até o mundo do progresso, onde estão localizados os países europeus e os Estados Unidos. Este mundo nega outros modos de pensar e inferioriza outras formas de conhecimento, construindo um desenvolvimento seletivo e opressor, que privilegia o econômico e transforma a natureza e as culturas em mercadorias para serem exploradas pelo capital. Nesta configuração, o pós-desenvolvimento surge como uma alternativa, uma crítica ao modelo exportador neocolonial defendido pelo desenvolvimento, uma forma de ler a realidade a partir de outras epistemes, reconhecendo a pluralidade dos mundos e a existência de novas possibilidades para constituir os territórios de vida.

O terceiro conceito elencado pela autora é a descolonialidade. A partir do reconhecimento de uma realidade estruturada em bases coloniais, que continuaram mesmo após o fỉm da colonização, é possível perceber que a atual sociedade moderno/colonial se legitima por meio da dominação desde as relações cotidianas, como, por exemplo, através da linguagem, até a naturalização de práticas econômicas, culturais, políticas, que hierarquizam os povos e impõem uma lógica contrária à estabelecida em seus territórios. Por meio desta contextualização, a autora demonstra a necessidade da desconstrução das relações e da construção de pensamentos e práticas descoloniais, de um agir e pensar que considere outras formas de conhecimentos e outras visões de mundo. A partir de novos parâmetros de leitura da realidade, criam-se diferentes possibilidades de atuação e de fortalecimento das lutas e rexistências dos povos, de uma autonomia que liberte.

Os debates expostos no livro provocam a concepção de novas formas de ver e vivenciar o mundo. Por meio das vivências em campo, apresentando a realidade dos camponeses/as do Brasil e da Colômbia, a autora demonstra as especificidades e elementos em comum dos conflitos e formas de r-existências, um resgate histórico para compreender os processos que constituíram a atual configuração destas comunidades, com o estabelecimento de marcos legais, que também representam conquistas adquiridas pela luta e persistências cotidianas destes povos e, por fim, uma análise teórica de conceitos que auxiliam na leitura de uma realidade que considere outros mundos e uma sociedade pluralizada. É por meio destes elementos que Mercedes Solá Pérez constrói uma pesquisa militante, que denuncia as violências, mas que possui como elemento central a reprodução da vida, as r-existências e as lutas dos povos agrários. 


\section{REFERÊNCIAS}

PÉREZ, Mercedes Solá. R-existências sociais pela vida - Camponesas e camponeses do que hoje é Suape (Brasil) e das Zonas de Reserva Camponesas (Colômbia). Curitiba: CRV, 2017.

PORTO-GONÇALVES, Carlos Walter. A Globalização da Natureza e a Natureza da Globalização. Rio de Janeiro: Civilização Brasileira, 2006. 